\title{
A 100 años de la Reforma Universitaria de Córdoba
}

\author{
Claudio Suasnábar \\ Universidad Nacional de La Plata-IdIHCS-CONICET, Argentina \\ csuasnabar@gmail.com
}

\section{INTRODUCCIÓN}

Los debates sobre la universidad, sus funciones y relación con el Estado en América Latina estuvieron signados, hasta pasada la mitad del siglo XX, por la proyección regional de la Reforma Universitaria de Córdoba cuyas ideas-fuerza marcaron, no solo la configuración que adoptaran las instituciones académicas sino también, el imaginario político de los actores y la función social de la universidad.

En este sentido, el Manifiesto Liminar de la Reforma no solo constituye el acta de fundación de este movimiento, sino también permite dar cuenta de las dos dimensiones que lo estructuraron como corriente de pensamiento. Por un lado, una dimensión programática que remite a las propuestas de cambio institucional alrededor de la idea de democratización de la universidad (el demos universitario que articula las nociones de co-gobierno y autonomía), y por otro, una dimensión u horizonte utópico que desborda la cuestión propositiva delimitando un imaginario discursivo de regeneración social cuyos rasgos principales se expresan en pares conceptuales como reforma universitaria y revolución social, crisis del antiguo régimen y nueva civilización, latinoamericanismo y antimperialismo, juvenilismo y vieja generación.

No es casual, entonces, que la proyección latinoamericana del ideario reformista haya adoptado diferentes configuraciones ideológicas según los países y tradiciones políticas que reapropiaron y resignificaron aquel corpus de ideas. Así, en la década de 1920, el peruano José Carlos Mariátegui y el cubano Julio Antonio Mella inscribirán el legado de la reforma en la continuidad del pensamiento marxista, mientras que Víctor Raúl Haya de la Torre, también peruano, encontrará en esas mismas ideas las razones para conformar un nuevo movimiento político: la Alianza Popular Revolucionaria Americana (APRA) de carácter nacional-popular.

Con todo, la década de 1940 marcaría el cierre de esta primera etapa de emergencia y proyección regional de la reforma universitaria, que estará signada por la conflictiva relación entre movimiento reformista y gobiernos populistas. Como bien señala Juan Carlos Portantiero (2012), refiriéndose al caso nacional, la histórica consigna reformista de la unidad obrero-estudiantil se quebraría ante la llegada del peronismo que encontraría a los estudiantes alineados en la trinchera opuesta a la de los obreros. Este comportamiento se explicaría -según este mismo autor- por la desorientación del movimiento reformista frente al confuso origen del peronismo que combinaría, de manera contradictoria, los componentes autoritario-corporativos de cuño fascista y la apuesta fuerte por la movilización e integración social de los sectores populares.

Las décadas del sesenta y setenta fueron sin duda el punto de mayor intensidad de los debates universitarios y el ideario reformista que, en el marco de una creciente radicalización política y movilización social, tendió a converger con los procesos políticos de transformación social en varios países. No es casual, entonces, que las principales reflexiones y propuestas de cambio para la universidad de los "intelectuales-rectores" como las de Risieri Frondizi en la Universidad de Buenos Aires, Darcy Ribeiro creador de la Universidad de Brasilia, Oscar Maggiolo rector de la Universidad de la República de Uruguay y Pablo González Casanova, rector de la Universidad Nacional Autónoma de México, entre muchos otros, se hayan inscripto como continuidad, y a la vez, superación del legado del movimiento reformista. El cierre de esta etapa vendría de la mano de las 
dictaduras militares que clausuraran no solo aquellas discusiones sino también las experiencias políticas de signo progresista.

La recuperación del debate sobre la universidad se inicia entre fines de los ochenta y comienzos de los noventa en un marco significativamente diferente al de las décadas anteriores. Un nuevo clima político y social, nuevas problemáticas y nuevas categorías teóricas delinean el escenario de fin de siglo XX donde emergerán, como gran foro de discusión, las Conferencias Regionales de Educación Superior (CRES) que impulsará la UNESCO como escala previa a las conferencias mundiales del sector. ${ }^{1}$ Así, los distintos documentos y declaraciones de las CRES dan testimonio no solo de la situación y tendencias de cambio en la educación superior de la región, sino también del esfuerzo por definir planes estratégicos y metas de logros que orienten las políticas públicas y acciones de los gobiernos y demás actores académicos. ${ }^{2}$

En coincidencia con el Centenario de la Reforma Universitaria, en un escenario regional caracterizado por la disputa respecto de la orientación de las políticas de educación superior, la tercera CRES sesionó en la ciudad de Córdoba durante el mes de junio de 2018. Ciertamente, la Declaración de Cartagena de la CRES 2008 marcó un punto de inflexión en el debate latinoamericano que, desplazando la tradicional formulación del derecho a la educación condicionado por el mérito, se instaló en la tendencia mundial de universalización de la educación superior. ${ }^{3}$ De esta manera, el derecho a la universidad (o más ampliamente a la educación superior) como "horizonte de época" ${ }^{4}$ marca un cambio paradigmático por cuanto implica una concepción de la democratización de la educación que desborda la cuestión del acceso, la permanencia y el egreso, y se ubica en la cuestión estratégica de la distribución y apropiación de conocimientos relevantes, pertinentes y de calidad.

En buena medida, este dossier dedicado a conmemorar los 100 años de la Reforma Universitaria presenta un conjunto de artículos que analizan y discuten tres momentos claves en la historia de este movimiento en Argentina y América Latina.

Así, el primer trabajo "Universidad y lucha de clases. La confluencia de obreros y estudiantes en la Córdoba reformista de 1918" de Eduardo Díaz de Guijarro de la Universidad de Buenos Aires retoma de manera renovada y original un viejo tópico, recurrentemente discutido en el momento fundacional, como es la caracterización y ubicación histórica del movimiento reformista. El artículo, que combina una exhaustiva revisión bibliográfica y fuentes documentales poco conocidas, muestra con mucha claridad "la profunda relación existente entre las luchas de la clase obrera cordobesa y el movimiento estudiantil que protagonizó la Reforma" que, como el mismo autor señala, se explica por el carácter capitalista de la economía cordobesa de principio del siglo XX y la existencia de una oligarquía que monopolizaba el poder económico, político y cultural de la provincia. Más aún, el análisis de las distintas movilizaciones desarrolladas durante 1918 muestra que, lejos de ser un conflicto restringido a la universidad, expresaba la convergencia entre obreros y estudiantes como parte de un capítulo de la historia de la lucha de clases en la Argentina.

El segundo trabajo de este dossier, "Reforma, peronismo y Universidad Obrera: un análisis comparativo en torno a dos modelos universitarios" de Sebastián Koc Muñoz, sociólogo egresado de la FaHCE de la Universidad Nacional de La Plata, explora otro momento crítico de la historia de la reforma universitaria como es el surgimiento del peronismo y la impronta que dejará este movimiento político en la universidad argentina. El trabajo focaliza su interés en los puntos de continuidad y ruptura entre el modelo reformista y el nuevo modelo universitario impulsado por el peronismo, cuya expresión será la Universidad Obrera Nacional. Al igual que el trabajo anterior, el artículo combina una exhaustiva revisión bibliográfica y fuentes documentales originales que no solo permiten explorar con mayor detalle la experiencia de creación institucional, sino también comprender el escenario socio-histórico y los posicionamientos que asumieron los distintos actores universitarios y no universitarios

Y, por último, el trabajo "ENLACES, CRES y Regionalidad: algunas aproximaciones sobre la integración de los campos de educación superior en América Latina y el Caribe" de Mário Luiz Neves de Azevedo, Profesor e investigador de la Universidad Estadual de Maringá de Brasil, nos introduce en los debates recientes que 
prolongan las disputas y tensiones de la última Conferencia Regional desarrollada en Córdoba en 2018. En ese trabajo resultan también audibles ciertos ecos de la Reforma, como el latinoamericanismo inscripto en aquella idea-fuerza de una Patria Grande, que hoy se encarna en la problemática de integración regional y los modos de materializarla. En esta dirección, el autor analiza la formación de ENLACES (Espacio de Encuentro Latinoamericano y Caribeño de Educación Superior), iniciativa propuesta en la CRES 2008, sus límites y posibilidades, a la luz de la experiencia europea de integración y distintos enfoques conceptuales alrededor de las nociones de regionalismo, regionalización y regionalidad.

De manera general, podemos decir que los trabajos que aquí se presentan, dan cuenta de las huellas, legados y presencias de la Reforma Universitaria, pero sobre todo de la preocupación de los autores por comprender el sentido y función de las universidades latinoamericana en su historia y a futuro.

\section{REFERENCIAS}

Portantiero, J. C. (2012). Estudiantes y populismo. Revista Los Trabajos y Los Días. 3. La Plata. Facultad de Trabajo Social: Universidad Nacional de La Plata.

García Linera, A. (2012). Geopolítica de la Amazonía: Poder hacendal-patrimonial y acumulación capitalista. La Paz: Vicepresidencia del Estado Plurinacional de Bolivia.

UNESCO/IESALC (2008) Declaración de la Conferencia Regional sobre Educación Superior en América Latina y el Caribe de Cartagena de Indias. Caracas, Venezuela.

\section{Notas}

1 La Conferencia Regional de Educación Superior (CRES) es un evento que reúne representantes de las universidades públicas y privadas, asociaciones y redes académicas, sindicatos docentes, organizaciones estudiantiles y gobiernos de los países de la región, apoyada y auspiciada por la UNESCO a través del Instituto de Educación Superior de América Latina y el Caribe (IESALC).

2 La primera conferencia regional se realizó en 1996 en la ciudad de La Habana, mientras que la segunda se desarrolló en 2008 en la ciudad de Cartagena. Cada una de las conferencias estuvo signada por escenarios socio-políticos y económicos diferentes y por el lento proceso de construcción de una mirada regional de la educación superior, los cuales ciertamente dejaron su huella en el contenido de las declaraciones, en sus avances y limitaciones. De tal manera, si la primera conferencia se dio en el marco de procesos de reforma estructural de la década de 1990 y de mayor influencia de los organismos internacionales, la segunda conferencia estaría marcada por una coyuntura económica favorable para región y un amplio consenso político sobre la necesidad de recuperar la centralidad del Estado y desarrollar políticas orientadas revertir las consecuencias regresivas de las políticas de la década anterior.

3 La Declaración Final de Cartagena de la CRES 2008 se inicia sosteniendo de manera contundente que "La educación es un bien público social, un derecho humano y universal y un deber del Estado. Esta es la convicción y la base para el papel estratégico que debe jugar en los procesos de desarrollo sustentable de los países de la región" (CRES, 2008, p.1).

4 Adaptamos libremente la noción acuñada por García Linera (2012) de "horizonte de época” entendiéndola como el conjunto de representaciones y expectativas dominantes en un período histórico que condensan las disputas, tensiones y contradicciones, y a la vez, operan como marco de sentido de la acción de los actores. 